\title{
O LUGAR DA TEORIA E DA PRÁTICA EM CURSOS DE GRADUAÇÃO EM TRADUÇÃO
}

\author{
THE PLACE OF THEORY AND PRACTICE IN TRANSLATION UNDERGRADUATE \\ PROGRAMS
}

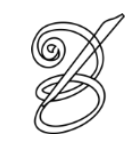

Samira SPOLIDORIO*

Universidade Estadual de Campinas, Brasil

\begin{abstract}
Resumo: Este trabalho faz parte de uma pesquisa de doutorado ${ }^{1} \mathrm{em}$ andamento, cujo principal interesse é estudar o ensino de tradução nos cursos de graduação de formação de tradutores no Brasil e, mais especificamente, a relação entre teoria e prática dentro desses cursos. Contudo, antes de chegar à análise dos projetos pedagógicos dos cursos propriamente ditos, é necessária uma maior reflexão tanto sobre a formação de tradutores quanto sobre o espaço universitário, a fim de embasar a discussão sobre a relação entre teoria e prática. Assim, o objetivo deste texto é contribuir para essa primeira etapa da pesquisa, trazendo pontos de discussão sobre a formação de tradutores nas salas de aula universitárias, assim como apresentar a importância da compreensão de que a teoria e a prática estão numa relação intrínseca e não dicotômica. Dessa forma, um dos nossos objetivos específicos aqui é apresentar a noção de que não existe prática sem teoria, ainda que seja uma teoria implícita (também chamada por alguns autores de "crenças"), que guia consciente ou inconscientemente as escolhas tradutórias. Assim, é papel dos cursos de formação de tradutores, sejam eles em nível universitário ou não, apresentar as teorias científicas de Tradução de forma que os tradutores em formação possam problematiza-las e, por meio de discussão teórica e prática reflexiva, possam de fato compreender a riqueza e a necessidade de se conhecer as teorias de Tradução para a formação de profissionais éticos, críticos e capacitados para as demandas do mercado e da sociedade.
\end{abstract}

Palavras-chave: Ensino de tradução. Formação de Tradutores. Teorias de Tradução. Prática Tradutória.

Abstract: This paper is part of an ongoing Ph.D. research mainly interested is translation teaching in undergraduate programs for translators' education in Brazil and, more specifically, the relation between theory and practice within these programs. However, before we start analyzing the curricula of said programs, we need to expand the reflection both on translators' education and on the university environment, in order to set a foundation for discussing the relation between theory and practice. Thus, this text aims to add a contribution to our research by presenting some discussion points about translators' education at the higher education classrooms, also highlighting the importance of understanding that theory and practice are in an intertwinedand not dichotomic - relationship. One of our main goals is to present the notion that there is no practice without theory, even though the theory might be implicit (which is also called 'beliefs'), guiding, either consciously or unconsciously, the translation choices. Therefore, it is the translators' education courses' role to present the translation scientific theories in a way that translation students can question their implicit theories/beliefs. Through theoretical discussion and reflexive practice, they should be able to actually understand the richness and the need to know these theories in order to become ethical, critical and skilled professionals.

Keywords: Translation teaching. Translators' education. Translation Theories. Translation Practice.

RECEBIDO EM: 19 de agosto de 2019

ACEITO EM: 19 de novembro de 2019

PUBLICADO EM: janeiro 2020 


\section{Introdução}

"The sometimes heated debate on whether 'translators are born, not made' (NIDA, 1981) or 'made, not born' (HEALEY, 1978) seems rather pointless" (GILE, 2009, p.7).

citação que serve de epígrafe para esse texto representa a discussão que por muito
tempo imperou sobre o ensino de Tradução ${ }^{2}:$ traduzir é um dom nato ou uma
habilidade que pode ser aprendida?; é mesmo possível ensinar alguém a traduzir por meio de um curso de tradução ou só se aprende a traduzir traduzindo?. Como o próprio Daniel Gile aponta, atualmente, essa discussão é considerada ultrapassada e não é mais o centro das preocupações.

É inegável que algumas habilidades natas podem ser de grande ajuda na formação de profissionais da Tradução, mas a melhor forma de aperfeiçoar essas aptidões naturais e colocálas em prática é, sem dúvida, mérito dos cursos de formação. Se a importância da formação é indiscutível, o mesmo não se pode dizer das instâncias formadoras, uma vez que não há consenso sobre a melhor maneira de formar profissionais da Tradução. A saber, as possibilidades são muitas e bastante variadas, podendo ir desde oficinas isoladas e cursos de curta duração ministrados por profissionais da área (chamados de "cursos livres") a cursos universitários de extensão, graduação e pós-graduação (MARTINS, 2006).

Assim, nosso objetivo neste texto é discutir a questão da formação profissional de tradutores em suas diferentes esferas, antes de passar especificamente para a formação em nível universitário, em um curso de graduação. Feito isso, nosso intuito final é poder discutir um pouco mais sobre a importância do ensino de teoria e de prática nos cursos de graduação em Tradução.

\section{Formação de tradutores e o papel da universidade}

No Brasil, a tradução não é uma profissão regulamentada e apenas os profissionais da tradução juramentada seguem parâmetros pré-estabelecidos, ainda que nenhuma formação específica seja necessária ${ }^{3}$. Dessa forma, sem essa regulamentação oficial não há regulamentação específica para a formação de tradutores (o que também acontece com outros profissionais como designers, fotógrafos, etc.), diferentemente do que ocorre com profissionais das áreas da Enfermagem, da Educação, da Engenharia, entre outros (que dispõem de regras bem estabelecidas para a formação e/ou credenciamento para atuação profissional por meio de ordens ou conselhos nacionais). 
Retomando nossa epígrafe, concordamos com Gile quando afirma que

educação formal não é obrigatória, mas pode ter, pelo menos, duas importantes funções: uma é a de ajudar pessoas que querem trabalhar profissionalmente com tradução e interpretação a aprimorarem seu desempenho e descobrirem seu potencial; a outra é a de ajudar a desenvolver habilidades de tradução de forma mais rápida do que por meio da experiência prática e autodidata que, em geral, pode envolver caminhar às cegas e ter que se basear em um método de tentativa-e-erro ${ }^{4}$ (GILE, 2009, p. 7, tradução nossa).

Essas duas funções, embora não sejam as únicas, são as mais óbvias e facilmente comprovadas quando se frequenta uma sala de aula de Tradução. A primeira delas é facilmente constatada quando perguntamos ${ }^{5}$ aos alunos qual a razão de terem escolhido estudar Tradução, obtendo como resposta, em sua maioria, alguma variação de "sempre gostei de ler livros de ficção e gostaria de poder traduzir literatura/ficção", ainda que a tradução audiovisual, em especial a legendagem, tenha ganhado bastante espaço nos últimos anos. Até o fim do curso, muitos desses aspirantes a tradutores de literatura/ficção vão se deparar com uma gama muito maior de possibilidades de atuação sobre as quais, até então, nunca haviam refletido, como as áreas da tradução técnica, científica, comercial, jurídica, midiática, publicitária, jornalística, entre outras, podendo descobrir uma facilidade extra ou um interesse em particular para uma delas.

A segunda função apontada por Gile (2009), embora não seja tão facilmente comparável, também costuma ser possível de ser mensurada. Tanto em relatos da literatura quando em nossa experiência profissional, a maioria dos alunos apresenta uma curva de aprendizagem bastante distinta e acentuada ao terminar o semestre e o curso. Esse aprendizado é notado, por exemplo, em relação ao uso das convenções textuais para cada área da Tradução trabalhada em comparação com textos de disciplinas anteriores ou com um texto diagnóstico geralmente pedido no início do semestre. Assim, ainda que Gile (2009) não esteja relatando necessariamente da realidade brasileira, suas reflexões se encaixam muito bem no dia a dia de nossos alunos.

O autor fala ainda sobre outras vantagens, ditas secundárias, que a formação específica em Tradução pode vir a ter, considerando tanto aspectos práticos quanto a possibilidade de melhorar os padrões profissionais enquanto classe trabalhadora, facilitando a entrada no mercado de trabalho por meio de contatos profissionais. Além disso, também se destacam a preparação para exames e certificações, o acesso ao conhecimento e à padronização de técnicas e de métodos de trabalho - podendo chegar à elaboração de um código de ética unificado -, 
assim como o desenvolvimento de aspectos mais subjetivos, como a sensação de pertencimento a um grupo profissional, o que é importante em uma profissão considerada solitária e autônoma. Muitas vezes, os primeiros colegas de trabalho e as parcerias que os tradutores em formação têm em seus anos iniciais de profissão são colegas de classe, professores ou pessoas que conheceram na universidade.

Nesse sentido, entre as pesquisas na área desenvolvidas no Brasil, Martins apresenta ideias semelhantes às mencionadas acima ao afirmar que

o principal objetivo de um curso de formação de tradutores, não importa o nível, sempre foi levar o aprendiz a adquirir competência tradutória e a integrar-se com sucesso à comunidade de profissionais da área, o que implica conhecer as normas e convenções que regem o comportamento dos membros dessa comunidade ao interagir tanto internamente quanto com outras comunidades às quais prestam seus serviço" (MARTINS, 2006, p. 27).

Essas reflexões são importantes para o início da discussão pretendida aqui por valorizarem a necessidade de formação de profissionais da Tradução, contrariando o pensamento propagado pelo senso comum de que para trabalhar com tradução basta saber duas línguas. Pensamento esse que, inclusive, é utilizado de forma incoerente por alguns profissionais da área a fim de vender seus cursos de curta duração (Figura 1).

Figura 1 - Comentário sobre formação na área de Tradução

\section{Mercado de Tradução: E preciso de Formação na Área?}

Em debates sobre a atuação no mercado de tradução, há basicamente duas correntes de pensamento:

1. A primeira defende que para se tornar um tradutor de sucesso é preciso ter uma graduação em tradução ou no campo da linguística.

2. A segunda acredita que basta saber um segundo idioma (essa é a linha de pensamento que defendo).

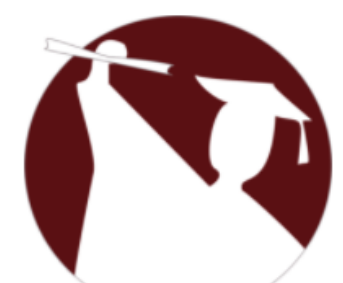

Na minha opinião, o primeiro grupo - que dissemina a ideia de que possuir uma graduação ou formação na área de tradução é condição necessária para ser tradutor - é formado por profissionais que tentam formar uma reserva de mercado para seu próprio grupo. Ou seja, ao dizer que apenas pessoas do seu meio são qualificadas

Fonte: Mercado (2019) .

Curiosamente, vemos que a equipe do site tenta usar desse argumento de que "basta saber duas línguas para poder traduzir” justamente para vender cursos de Tradução, ou seja, 
cursos que, com maior ou menor sistematização e organização, visam apresentar a Tradução como área específica e que, portanto, exige formação. Assim, se a importância dos estudos e da formação são indiscutíveis até mesmo entre os que se dizem autodidatas (ABRATES, 2015; SOUZA, 2017), o mesmo não se pode dizer das instâncias formadoras, uma vez que não há um consenso sobre a melhor maneira de formar profissionais da Tradução.

No Brasil, a Associação Brasileira de Tradutores (Abrates) realizou uma ampla pesquisa com cerca de 919 profissionais da Tradução (entre associados ou não) em que buscava descobrir, entre outros fatores como idade, sexo, localização geográfica, pares de idiomas de trabalho, faixa salarial, entre outros, a formação dos participantes. Abaixo, dispomos os gráficos que ilustram que a formação universitária (seja ela em nível de graduação ou de pós-graduação) representa menos de um terço da formação inicial e menos de dois quintos da formação continuada dos tradutores pesquisados.

Figura 2-Gráficos com o perfil de tradutores e intérpretes

Concluiu um bacharelado em tradução?

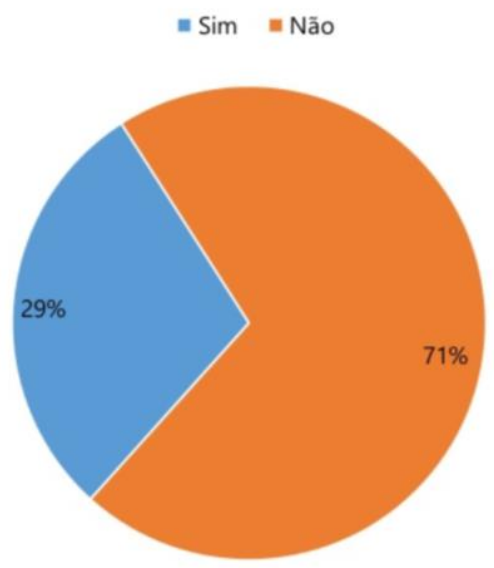

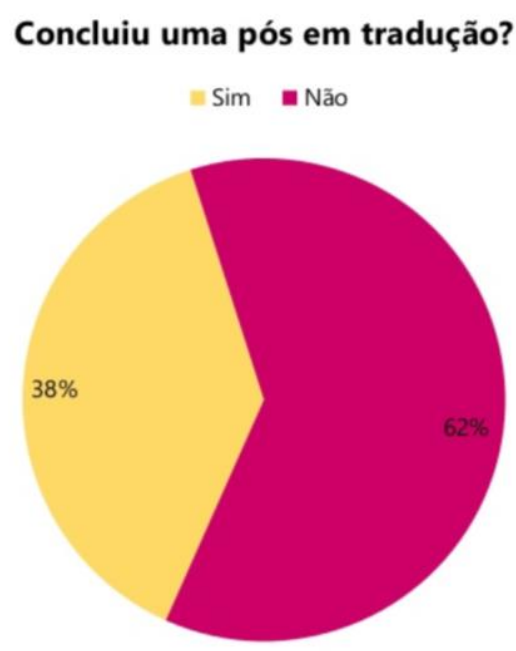

Fonte: Abrates (2015).

Infelizmente, a pesquisa não abordou a questão da formação profissional fora do ambiente universitário, mas nas comunidades online da área de Tradução, tanto no âmbito internacional - nos fóruns de discussão de sites como LinkedIn.com, Proz.com e TranslatorsCafé.com - quanto no nacional - páginas do Facebook -, é comum encontrarmos discussões sobre esse perfil. Nessas plataformas, muitos membros debatem os prós e os contras das diferentes opções e, de forma quase generalizada, parece prevalecer a ideia de que, embora a formação seja crucial, um curso universitário de graduação não seria a melhor alternativa. 
Essa diversidade tem como razão a falta de regulamentação oficial da profissão e, com isso, a falta de regulamentação para os cursos de formação.

Diferentemente do que acontece com cursos de licenciatura e bacharelados da área da Engenharia, por exemplo, não há parâmetros que regulamentem o exercício da profissão, possibilitando que qualquer pessoa possa trabalhar profissionalmente com tradução. A exceção é a tradução juramentada que exige aprovação em concurso público, porém qualquer pessoa de qualquer formação (ou até sem formação específica, bastando apenas o diploma do Ensino Médio) pode se candidatar para o concurso.

Em resposta a isso, uma de nossas hipóteses é que essa falta de regulamentação tem como consequência uma desvalorização da formação universitária frente à formação oferecida em outras instâncias, principalmente quando são comparados os investimentos de tempo e dinheiro para cursar uma graduação, considerando que mesmo um curso em uma instituição pública e gratuita acarreta em custos de moradia, transporte, alimentação, material escolar, entre outros. Assim, essa tendência decentralizadora parece estar em consonância com as ideias debatidas por Cocola (2006) quando aponta que há no senso comum a ideia de que

o conhecimento é o principal recurso econômico, servindo como pré-condição e fator de sustentação para a hegemonia econômica e/ou militar. Ainda assim, na era digital, não há qualquer razão para que as universidades sejam o lugar centralizador de todo o conhecimento existente e futuro. Nem razão para que seja centro de qualquer outra coisa $^{6}$ (COCOLA, 2006, p. 145, tradução nossa).

É impossível negar o valor econômico do conhecimento e ignorar que, hoje mais do que nunca, ele pode ser acessado e construído por meio de outras instituições e plataformas para além do ambiente universitário. Contudo, discordamos veementemente da afirmação de que a universidade "não deve ser o centro de coisa alguma", trazendo algumas das reflexões do filósofo Derrida (1990), quando discute o papel da universidade. Nos textos que compõem a extensa coletânea intitulada Du Droit à Philosophie (1990), Derrida apresenta o debate de vários aspectos sobre a importância da filosofia para a sociedade e o lugar do curso de Filosofia na universidade. Mais especificamente, no texto Mochlos ou o Conflito das Faculdades, presente também na edição brasileira do livro O Olho da Universidade (1999), o autor se dispõe a resgatar um antigo debate proposto por Immanuel Kant em 1798 sobre o status das diferentes faculdades dentro da universidade.

Derrida (1999) concorda com Kant (1798 apud DERRIDA, 1999) quanto à proposição de que a Faculdade de Filosofia, vista já à época de Kant como uma faculdade "menor" em 
relação às Faculdades de Teologia, Direito e Medicina, era na verdade a mais importante dentre as demais por não proporcionar só uma formação empregatícia (para clérigos, advogados e médicos, por exemplo), mas também crítica e reflexiva. Segundo o filósofo, a ideia de universidade calcada na Faculdade de Filosofia

está aí para dizer o verdadeiro, para julgar, para criticar no sentido mais rigoroso do termo, a saber, para discernir e decidir entre o verdadeiro e o falso; e, se ela também está habilitada a decidir entre o justo e o injusto, o moral e o imoral, é porque a razão e a liberdade de juízo estão implicadas (DERRIDA, 1999, p. 102).

Assim, conforme discutido por Lima e Spolidorio (2019), defender a visão de Derrida (1990, 1999) sobre a importância da universidade não é dizer que apenas a universidade está capacitada para oferecer a formação profissional necessária aos aspirantes a tradutor. Muito pelo contrário, ao se colocar como um ambiente aberto a questionamentos e experimentos, a universidade abre também espaço para a dúvida e isso não permite que ela se abstenha de quaisquer críticas e questionamentos sobre seu papel na sociedade.

Ainda sobre esse papel da universidade, outro texto de Derrida que pode nos fornecer subsídios para pensar essa questão é o ensaio Universidade sem condição (2003), no qual ele afirma que

a universidade moderna deveria ser sem condição. [...] Para além do que se chama de liberdade acadêmica, essa universidade exige e deveria ter reconhecida uma liberdade incondicional de questionamento e proposição, ou até mesmo, e mais ainda, o direito de dizer publicamente tudo o que uma pesquisa, um saber e um pensamento exigem (DERRIDA, 2003, p. 13-14).

Nesse sentido, Lima e Spolidorio (2019) discutem o duplo sentido (tão característico dos textos de Derrida como seu double bind) da expressão "sem condição" que "refere-se tanto ao fato de não ter condições ou ser impedido de agir, por conjunturas diversas, como também ao fato de poder agir sem que sejam impostas condições, ou seja, ter uma atuação soberana" (LIMA; SPOLIDORIO, 2019). Assim, a universidade deveria ser ao mesmo tempo “incondicional" no sentido de não sofrer com imposições ou condições para sua existência, mas é, em realidade, "sem condições", pois não tem esse seu lugar de direito respeitado verdadeiramente.

Assim, se os outros cursos de formação de tradutores disponíveis fora da universidade veem como dispensável a reflexão teórica, a universidade passa a ser, por excelência, o local para essa discussão. Afinal, apesar da possibilidade da formação de profissionais de qualidade 
fora dos muros da universidade ser uma verdade incontestável, um curso sistematizado e organizado para prover ao corpo discente um ambiente crítico-reflexivo e não apenas as habilidades práticas é de fundamental importância.

A reflexão teórica é, portanto, ao mesmo tempo dever e privilégio da universidade. Configura-se como um privilégio, pois, fora da universidade, o número de profissionais com interesse em participar dessas discussões parece ser consideravelmente menor. Conforme as discussões encontradas nas comunidades online (e exemplificadas mais a diante), profissionais já atuantes no mercado de trabalho ou aspirantes que buscam cursos de formação voltados apenas para a prática tendem a relegar a teoria a segundo plano, relatando, entre outros motivos, falta de tempo para se dedicar às leituras, às pesquisas, aos debates, às discussões e a outras atividades inerentes ao ambiente universitário.

Além do mais, como colocou Derrida (1999), se cabe aos "sábios" da universidade formar outros sábios, então é nela que poderemos encontrar mais facilmente (ainda que não exclusivamente) docentes com a capacitação necessária para propor, explorar e moderar a reflexão teórica necessária. Assim, é dever dessa instituição, que dispõe do tempo, do espaço,

174 dos meios e da capacidade de promoção dessas discussões éticas, culturais, teóricas e críticas, ser o lugar da reflexão e da pesquisa.

Lembrando a colocação de Cocola (2006) sobre o valor mercadológico do conhecimento, é importante destacar também que muitas das discussões propostas pelas teorias da área, longe de apenas estabelecer conceitos abstratos e filosóficos que em nada se aproximam da prática da profissão, tratam de questões bastante concretas como a visibilidade e a representatividade de profissionais da Tradução. Dessa forma, parece-nos que, ao resgatar e refletir sobre questões relacionadas ao poder histórico, político e social da Tradução, profissionais da área teriam uma maior compreensão da importância do papel que desempenham num mundo globalizado e interconectado como o nosso. Numa visão talvez utópica, acreditamos que essa compreensão poderia mudar o paradigma do mercado de trabalho, colocando profissionais da área em uma posição real de negociação em relação, por exemplo, às duas maiores reclamações da categoria: melhores condições de trabalho e de remuneração.

Ainda que, de fato, a universidade não seja necessariamente a força centralizadora de todo o conhecimento, há, sim, algo que lhe é próprio e que outros cursos de formação na área de tradução parecem não oferecer: a possibilidade de aliar reflexão crítica e teórica sobre tradução com a prática. Como por exemplo, em vários momentos de discussão dentro das 
comunidades online anteriormente mencionadas, vários membros expressaram opiniões estanques e dicotômicas sobre a relação entre teoria e prática, afirmando (alguns até bem categoricamente) que a teoria é apenas para os estudos acadêmicos da pós-graduação e nada tem a ver com o mercado de trabalho e a profissão em si.

A título de exemplo, tomemos a Figura 3, na qual vemos a captura de tela de uma enquete proposta por uma tradutora profissional e professora de Tradução, questionando colegas da área sobre suas preferências em vistas da elaboração de um minicurso:

Figura 3 - Enquete publicada no grupo Tradutores / Intérpretes do Facebook

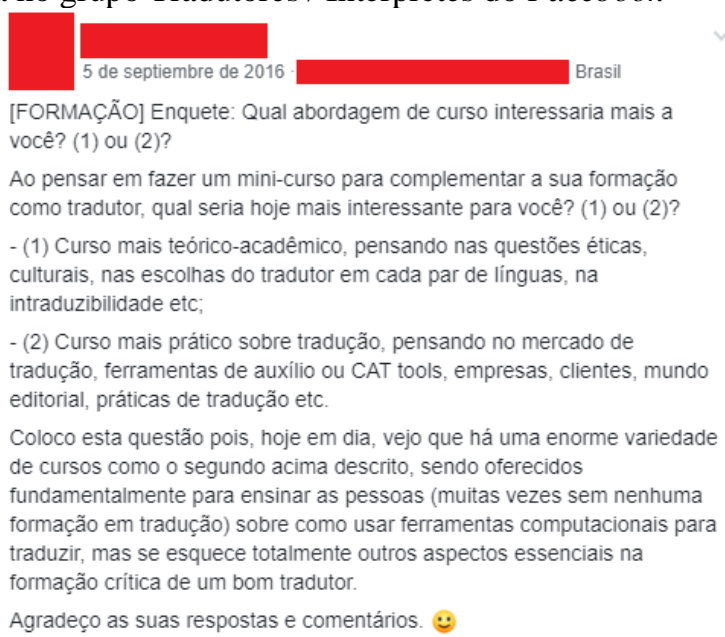

Fonte: R.E.M. ${ }^{7}$ (2016).

Sem muita surpresa, profissionais da área quase que unanimemente (doze das treze pessoas que responderam) escolheram a opção dois ainda que, como a proponente do minicurso salientou, já existem muitas opções dessa natureza disponíveis.

Figura 4 - Colagem de várias respostas para a Enquete da Figura 3 (as cores diferentes indicam pessoas diferentes, enquanto a mesma cor indica a resposta ou referência a mesma pessoa)

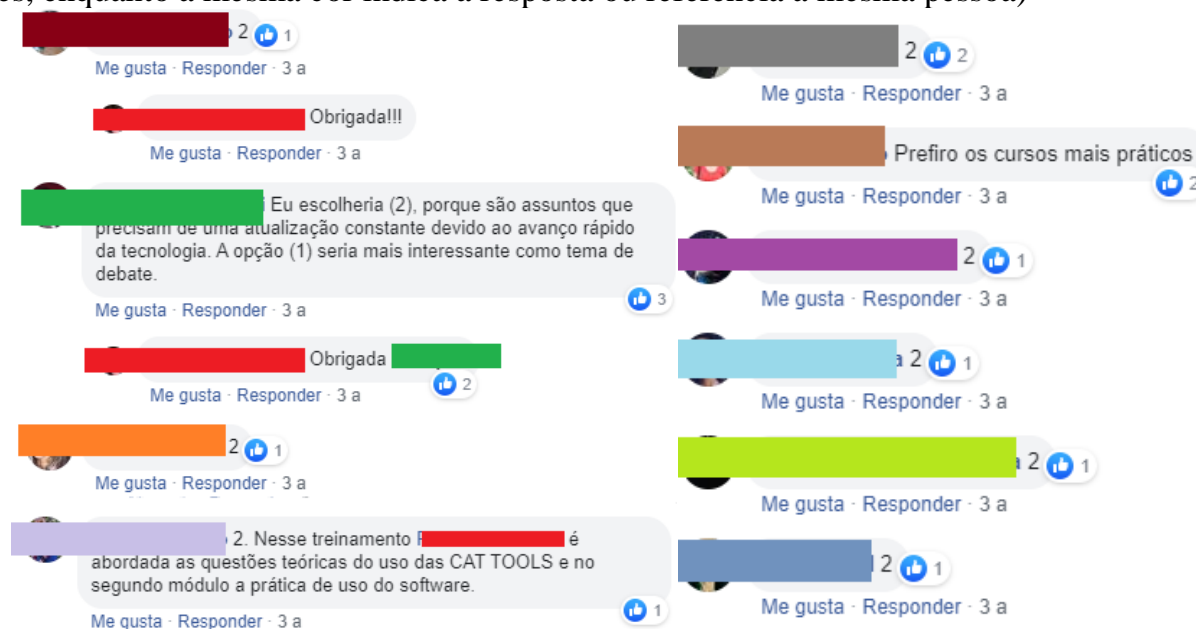

Fonte: Vários autores ${ }^{7}$ (2016).

SPOLIDORIO, Samira. O lugar da teoria e da prática em cursos de graduação em tradução. Belas Infiéis, Brasília, v. 9, n. 1, p. 167-186, 2020. 
Assim, além da preferência quase que total por cursos de teor mais prático, chamou atenção também a resposta de algumas pessoas ao indicarem implícita e até explicitamente a "inutilidade" da discussão teórica para a formação profissional na área de tradução. Como um curioso exemplo das respostas dadas à enquete, uma longa explicação foi oferecida por uma participante que afirmava que os dois minicursos propostos teriam objetivos diferentes:

Figura 5 - Resposta à Enquete da Figura 3

ter púo objetivos diferentes e os dois sempre vão
cursos que normalmente seguem a estrutura acadêmica como
graduação, pós Lato Sensu, Mestrado e Doutorado são para quem
quer esse tipo de embasamento e exercicio reflexivo e, também,
para quem pretende fazer carreira na academia. Os cursos livres
normalmente buscam abordagens mais práticas, embora muitos
incluam pelo menos um módulo de embasamento teórico. Os
cursos livres buscam preencher lacunas deixadas pela formação
universitária. A maioria dos nossos cursos acadêmicos ainda
falham na parte prática, nos aspectos tecnológicos, na sintonia com
o que o mercado exige do tradutor. Como aqui nos grupos
encontramos pessoas em busca de crescimento profissional, em
busca de oportunidades no mercado, a demanda por cursos que
preencham as lacunas da formação e atualizem o conhecimento
técnico é muito grande até por que a área de tradução ainda é
muito fechada em admitir quem vem de outras áreas de formação
na carreira acadêmica na área de modo que quem busca uma
formação reflexiva, vindo de outras áreas, tem seu ponto final na
pós Lato Sensu. Assim, a perspectiva de retorno profissional é
limitada se o profissional não se interessar em fazer nova
graduação.
Me gusta - Responder - 3 a

Fonte: P.C. ${ }^{7}$ (2016).

Na resposta acima, fica clara a opinião de que profissionais que já trabalham na área não se interessam por discussões sobre questões éticas e culturais, assim como sobre particularidades específicas de cada par linguístico, resultantes do status político e social das culturas a que cada uma das línguas pertence, ou mesmo de questões mais filosóficas como a da intraduzibilidade. Assim, segundo a maioria das opiniões expressas nessas discussões, e reforçada pelo número de curtidas que as respostas obtiveram, para quem já está ou então para quem almeja entrar no mercado e não tem pretensão de seguir carreira acadêmica por um mestrado ou doutorado, a reflexão teórica não tem espaço na formação profissional, que deve ser voltada puramente para atualizações tecnológicas e habilidades práticas.

Outro ponto interessante levantado na resposta que selecionamos é que, supostamente, os cursos universitários "falham na parte prática", em especial no que diz respeito às tecnologias e às tendências do mercado. Consideramos essa opinião desatualizada, uma vez que estudos recentes, como os de Collet (2016) e Souza (2017), mostram que os cursos universitários têm 
visado oferecer disciplinas voltadas para as áreas em maior crescimento no mercado, como a de tradução audiovisual e a de tecnologias, respectivamente.

Além das pesquisas acadêmicas, há também um movimento ainda pequeno, mas que tem crescido nos últimos meses, das agências internacionais não só dando preferência para profissionais freelancers com formação específica em Tradução, mas em alguns casos exigindo o diploma universitário para iniciar o processo de seleção. Ainda que não seja possível identificar com exatidão a força motriz por trás dessa aparente mudança ${ }^{8}$, o fato é que, atualmente, existem mais de 350 cursos de formação no mundo (VENUTI, 2017), sendo 28 deles no Brasil (COSTA, 2018), e a tendência é que esse número continue crescendo. Assim, estudos sobre a formação de profissionais da tradução, que é oferecida por esse crescente número de instituições, são de extrema importância para entendermos o contexto em que essa formação se dá.

\section{A relação entre teoria e prática na formação de tradutores}

Pym (2009) faz uma interessante retrospectiva da formação de tradutores na história e aponta que ela esteve, por muito tempo, atrelada a questões de controle, de domínio e de autoridade por meio da relação de mestre-aprendiz, comum às Artes. Desde a Antiguidade Clássica e principalmente durante o domínio da Igreja Católica na Idade Média, a formação de tradutores visava "não só [...] assegurar a qualidade de desempenho, mas também [...] controlar a lealdade dos tradutores" (PYM, 2009, p. 3, tradução nossa) ${ }^{9}$, o que, em muitos casos, era um fator ainda mais importante do que a suposta precisão na tradução.

Opinam também sobre antiga polêmica dicotomia "teoria versus prática" os autores Chesterman e Wagner (2002), que em seu livro Can theory help translators: a dialogue between the ivory tower and the workforce, apresentam uma série de argumentos a favor e contra a relação da teoria e da prática na formação de tradutores.

Segundo esses pesquisadore ${ }^{10}$, essa divisão entre o saber teórico e o saber prático já era comum na Antiguidade Clássica, porém, naquela época, os valores eram invertidos. Com a filosofia grega sendo uma das mais altas formas de intelectualidade, o trabalho manual era relegado a servos e a escravos, disfrutando, portanto, de pouco ou mesmo nenhum prestígio social. Durante toda a evolução da Idade Média e da Era Moderna, essa hierarquia se manteve, atingindo seu ápice na época do Iluminismo, quando o conhecimento se tornou o aspecto mais valorizado da sociedade. 
Foi apenas com a chegada da Revolução Industrial - e a consequente necessidade de habilidades práticas dos trabalhadores no mercado emergente - que a formação prática, no saber fazer (o famoso know how), começou a ganhar força. A partir de então, esse saber ganhou cada vez mais destaque, ainda que o prestígio social tenha continuado a ser atrelado aos saberes intelectuais por um bom tempo. Atualmente, como mostram os comentários selecionados acima e tantos outras opiniões do senso comum, o saber prático costuma superar o saber teórico tanto em destaque (por ser o que as pessoas mais buscam) quanto em prestígio (por ser o que as pessoas mais respeitam).

Ademais, também temos autores brasileiros contribuindo para essa discussão. Segundo Gonçalves e Machado (2006), a polarização entre teoria e prática é bastante comum e se manifesta na forma de

uma divergência bastante recorrente, tanto no universo acadêmico quanto profissional, refere-se à diretriz didático-metodológica a ser adotada na formação do tradutor e pode ser expressa pela dicotomia treinamento prático (automatização/desenvolvimento de conhecimentos procedimentais - saber como) versus reflexão teórica (conscientização/desenvolvimento de conhecimentos declarativos - saber o quê) (GONÇALVES; MACHADO, 2006, p. 47-48).

Voltando a Chesterman e Wagner (2002), o cerne desse problema na relação entre teoria e prática está na concepção equivocada de "o que é" e "para que serve uma teoria". O senso comum, como bem apresenta Wagner em suas proposições e argumentos contra Chesterman, pressupõe que uma teoria seja um modelo ou fórmula que possa ser "aplicada" na prática, como uma lista de instruções a respeito de "como fazer" ou de "como fazer melhor". Os teóricos e estudiosos da tradução obviamente falham ao explicar que uma teoria é um conjunto de proposições (muitas vezes abstratas, é verdade) que observam, descrevem e ajudam a entender o processo tradutório já realizado e, mais recentemente, o impacto e a influência que as traduções e os tradutores acabam tendo na sociedade.

Fawcett e Garcia (2010), por sua vez, concordam com esse ponto, ao afirmarem que

um conhecimento da teoria - mais especificamente de um amplo repertório de teorias, e não de uma teoria-chefe única - pode ser uma ferramenta poderosa nas mãos de profissionais da tradução, ajudando a entender as várias formas em que a prática tradutória pode ser construída. Tais teorias podem ser teorias de ou sobre tradução, ou mesmo teorias de fora do campo da tradução, que podem proporcionar, tanto para quem pratica quanto para quem estuda, uma melhor compreensão do fenômeno da tradução como ela realmente é. Da mesma forma, a prática em si também vai, inevitavelmente, influenciar a teoria, ou assim deveria ser $^{11}$ (FAWCETT; GARCIA, 2010, p. 2, tradução nossa). 
Dentre os representantes de estudos feitos no Brasil sobre o assunto, o saudoso Aubert, que tanto contribuiu para os avanços dos Estudos da Tradução no país, também concorda com essa proposição, enfatizando que a prática também é inevitavelmente afetada pela teoria. $\mathrm{O}$ autor comenta a importância das teorias para o que ele chama de "prática consciente", afinal,

é da teoria, ou da teorização, que derivam as práticas conscientes, lúcidas, capazes, a qualquer tempo, de se justificarem, de se defenderem, de se imporem [...]. Da teorização nasce a conscientização (awareness). É a partir da teorização que se faz uma prática verdadeiramente profissional (AUBERT, 2003, p. 14-15).

Assim, a partir dele e da discussão feita até aqui, estabelecemos o ponto crucial deste trabalho que é afirmar que não existe prática sem teoria/teorização, seja ela consciente ou não. Outra pesquisadora brasileira que possibilita essa nossa asserção é Pungartnik (2015), que em sua dissertação de mestrado afirmou que

o comportamento profissional do tradutor revela que um tradutor que tende a se
preocupar apenas com as construções gramaticais do texto poderá refletir uma
preocupação linguística que determinará seu procedimento e esse tipo de tradutor
entende que a construção do seu texto terá sucesso, caso ele apresente um texto
impecável em sua forma. De outro modo, um tradutor que reflete sobre seu trabalho
fora de uma perspectiva logocêntrica estará preocupado com a profunda interpretação
textual e extratextual e não terá medo de imprimir sua própria identidade no texto que
produz. São posições que não dependem de uma pré-concepção a priori, que ele
imponha a si mesmo, mas resultantes de sua trajetória (PUNGARTNIK, 2015, p. 41).

Da mesma forma, outros autores também postulam que as preconcepções (sejam elas baseadas em teorias ou no senso comum) que os profissionais têm sobre a tradução vão, invariavelmente, afetar seu desempenho profissional. Entre os brasileiros que discutem essa questão, damos destaque a Pagano (2003) que apresenta o conceito de "crenças", ou seja, "todo pressuposto a partir do qual o aprendiz constrói uma visão do que seja aprender e adquirir conhecimento" (PAGANO, 2003, p. 9). Esses pressupostos são determinantes para a escolha dos recursos e a estratégia que o aprendiz utilizará para resolver problemas que surgirem ao longo de seu aprendizado e que influenciam também na decisão de "o que", "como", "quando" e "em quanto tempo" aprender.

Por sua vez, Esqueda e Oliveira (2013) também emprestam da área do ensino e aprendizagem de idiomas a proposição de "crenças e concepções", citando uma variedade de autores tanto da área da Educação quanto da área da Tradução, que apresentam argumentos semelhantes a respeito da força e do determinismo que determinadas crenças podem ter no 
processo de aprendizagem dos estudantes. A partir de um questionário aplicado a alunos ingressantes de um curso de tradução, as autoras constataram que

\begin{abstract}
a maioria dos ingressantes possui a crença de que a tradução é a transferência de informações de uma língua para outra, não devendo "fugir" do original; que a atividade de tradução requer conhecimento linguístico; de que o tradutor deve ter as mesmas habilidades de um professor de idiomas, sendo que a maioria dos ingressantes expressou o desejo de aperfeiçoar e adquirir mais conhecimentos linguísticos, [...] e ainda percebe a tradução como transferência de significados, como sendo uma atividade simples que pode ser executada com bons dicionários e conhecimento linguístico (ESQUEDA; OLIVEIRA, 2013, p. 159-160).
\end{abstract}

Essas crenças iniciais detectadas pelas autoras, invariavelmente determinam a ação tradutória dos profissionais em formação que, por terem fortes crenças - como a falácia da equivalência, da fidelidade e da invisibilidade, sobrepondo o texto original ao texto traduzido e se baseando unicamente no conhecimento linguístico de dois idiomas - , tendem a produzir traduções com severas marcas dessa mentalidade limitadora. Ainda na mesma pesquisa, as autoras constataram que essas crenças influenciam muito nas expectativas sobre o curso de Tradução:

os ingressantes, em sua maioria, possuem as seguintes expectativas: de adquirirem conhecimento das várias áreas da tradução, para que sua contratação possa ser facilitada; de que ser fiel ao texto original é o indicador de uma boa e aceitável tradução; de que o tradutor competente não deixa o público perceber que se trata de uma tradução; de que a teoria é importante e auxilia a prática, sem mencionarem exatamente como isso ocorre; de que conhecimentos culturais são importantes para se manter a fidelidade ao texto original; de que o leitor em prospecção é o que guia a boa tradução (ESQUEDA; OLIVEIRA, 2013, p. 160-161).

No âmbito internacional, Presas Corbella e Martin de León (2014) têm desenvolvido pesquisas com abordagem semelhante sob a nomenclatura de "teorias implícitas". As autoras reconhecem que outras terminologias, como "conhecimento cotidiano, teorias tradicionais, teorias subjetivas e crenças" 12 (PRESAS CORBELLA; MARTIN DE LEON, 2014, p. 275. Tradução nossa) também são usadas para denominar a noção de "teorias implícitas" defendidas por elas. Segundo elas,

o papel das teorias implícitas no processo de tomada de decisões perpassa uma área muito ampla, desde relacionamentos pessoais e políticos, até a vida pessoal e professional de uma pessoa. Até o presente momento, os Estudos da Tradução têm dedicado pouca atenção para a influência que o conhecimento e as crenças no processo de tradução e menos ainda para o papel das teorias implícitas ${ }^{13}$ (PRESAS CORBELLA; MARTIN DE LEON, 2014, p. 275, tradução nossa). 
Em seu projeto de pesquisa-piloto, as autoras monitoraram uma turma de tradutores em formação durante um semestre em uma disciplina teórico-prática. Em resumo, a pesquisa consistiu em verificar por meio de um questionário suas crenças iniciais a respeito de "o que é traduzir", analisando quais metáforas eram usadas para descrever esse processo. Depois de um semestre de discussão teórica e atividades práticas, um novo questionário foi aplicado, a fim de comparar as respostas do fim do semestre com as dadas no início do curso. Assim, por meio de uma minuciosa apresentação da metodologia de coleta e análise de dados, as autoras destacam como principais descobertas do estudo o que elas chamam de "mudança conceitual", que vem a ser a mudança nas teorias implícitas (ou crenças) apresentadas pelos tradutores em formação no primeiro questionário em relação ao uso de "teorias explícitas", ou seja, de teorias científicas apresentadas e discutidas durante o semestre, por meio das diferentes metáforas e explicações dadas pelos alunos nos dois questionários avaliados.

A partir de dados coletados nesse e em outros estudos, Presas (2017) propõe o esqueleto de uma sequência pedagógica que possa ajudar a promover "a mudança conceitual ao focar nos processos que levam os alunos a reestruturarem suas concepções iniciais" (PRESAS, 2017, p. 520, tradução nossa ${ }^{14}$ ). Dentro dessa proposta didática, cinco etapas são apresentadas (PRESAS, 2017, p. 528-530):

\footnotetext{
1. Ativação das teorias iniciais, em que os alunos sistematizam e explanam o que trazem de conhecimento prévio, com crenças e teorias implícitas.

2. Promoção do conflito cognitivo, em que os alunos percebem que suas concepções iniciais apresentam falhas de aplicação ou que eles não dão conta de todo o processo tradutório.

3. Combinação de teoria e prática, em que os alunos usam as teorias científicas apresentadas para refletirem e realizarem as tarefas tradutórias.

4. Promoção de processos metacognitivos, em que os alunos refletem, também a posteriori, sobre seus processos tradutórios e suas traduções.

5. Enfrentamento das características individuais, oferecendo aos diversos perfis de alunos diferentes estratégias para chegar à mudança conceitual necessária, uma vez que, por exemplo, alguns podem ter um perfil mais racional e autoconfiante, enquanto outros podem responder melhor à motivação e a emoções.
}

Embora a autora não dê um plano de aula completo a ser seguido nem traga relatos de resultados obtidos, consideramos que a estrutura da sequência didática apresentada é bastante útil para começarmos a pensar em aulas teórico-práticas que possam ajudar nossos alunos a sair de suas crenças/teorias implícitas e possam de fato refletir sobre a importância das teorias científicas da área. Fica, então, para estudos futuros, a incumbência de explorar mais essa sequência e colocá-la em teste. 


\section{Considerações finais}

Como vimos com Pym (2009), as instâncias de formação profissional e também os conteúdos abordados carregaram por muito tempo um peso de parcialidade e de controle autoritário. Isso também remete à divisão dicotômica entre teoria e prática não só no que se refere à tradução, mas também a outras áreas, ainda que a valorização do conhecimento prático sobre o conhecimento teórico seja um fenômeno relativamente atual, ainda que extremamente presente e forte.

Assim, após a reflexão proposta aqui sobre a importância da formação de tradutores e o espaço único que a universidade oferece para isso, retomamos as conclusões de Lima e Spolidorio, de que:

\footnotetext{
se pensar é traduzir [o pensamento em palavras], nada como o espaço universitário para nos oferecer oportunidades de colocar o pensamento em ação. A universidade é o lugar, por excelência, para a discussão de questões críticas. A ideia da desconstrução derridiana e suas considerações sobre a universidade tratam exatamente deste ponto: o desconstruir-se da universidade, para o qual o incessante questionamento é fundamental (LIMA; SPOLIDORIO, 2019).
}

Dessa forma, acreditamos que embora a presente situação $^{15}$ ainda esteja longe da ideal e demonstre claramente que ainda há muito a ser conquistado, tanto no que diz respeito ao espaço dentro da universidade quanto em relação à valorização da profissão, a universidade tem um papel vital no cenário almejado. Contudo, para que as mudanças fora dos muros universitários ocorram, é preciso que haja transformações internas, nas salas de aula de tradução, que possibilitem uma revolução de dentro para fora.

Para argumentar em favor dessa mudança, apresentamos diversos autores nacionais e internacionais que têm já há algum tempo discutido a necessidade de alterarmos o status dessa dicotomia estanque e apresentarmos a prática do processo tradutório como algo indissociável da teoria, de fonte consciente ou não. Nesse sentido, é imperioso considerarmos o alerta de Presas (2017) sobre o uso das teorias implícitas pelos tradutores em formação:

alunos têm teorias implícitas que eles usam em seus processos tradutórios. Podemos pressupor que, para os alunos, essas teorias funcionam como um instrumento de interpretar situações e definir objetivos. Contudo, temos evidências que também demostram que, em geral, essas teorias caracterizam a tradução e seus fenômenos relacionais de forma parcial e superficial, sendo aplicadas independentemente das considerações contextuais. Dessa forma, essas teorias são um fator que contribui para resultados inadequados, ou pelo menos imprevisíveis ${ }^{16}$ (PRESAS, 2017, p. 531. Tradução nossa). 
Assim, entre o desejo da transformação e a contingência dos riscos de sua aplicação, fica a nosso cargo continuar pensando e refletindo a respeito de mais possibilidades de levar a reflexão teórica e a prática reflexiva para dentro de nossas salas de aula, a fim de formarmos tradutores mais conscientes, éticos, responsáveis, capacitados e críticos.

\section{REFERÊNCIAS}

ABRATES. O perfil profissional dos tradutores e intérpretes no Brasil. 2015. In: SLIDESHARE: LinkedIn Corporation, 2019. Disponível em: https://pt.slideshare.net/Abrates/o-perfil-profissional-dos-tradutores-e-interpretes-no-brasilabrates-2015. Acesso em: 9 dez. 2019.

AUBERT, Francis Henrik. Diálogos da prática com a teoria. In: BENEDETTI, Ivone C.; SOBRAL, Adail. Conversas com Tradutores: balanços e perspectivas da tradução. São Paulo: Parábola Editorial, 2003.

CHAIA, María Claudia Geraldine. Los traductorados en Argentina: una aproximación al estado de la cuestión. In: ATENEO INTERUNIVERSITARIO DE TRADUCTOLOGÍA, 2. 2014, Buenos Aires, Argentina. La formación para la traducción. Buenos Aires:

Universidad Nacional de La Plata, 2014. Disponível em:

https://www.researchgate.net/publication/278158187_Los_traductorados_en_Argentina_una_ aproximacion_al_estado_de_la_cuestion. Acesso em: nov. 2019.

CHAIA, María Claudia Geraldine. Translation Studies Research at the Service of Translation Profession: A Case Study at Undergraduate Level. In: IATIS 5TH INTERNATIONAL CONFERENCE, 5., 2015, Belo Horizonte. Innovation Paths in Translation and Intercultural Studies. Belo Horizonte: 2015. Disponível em: https://www.researchgate.net/publication/280529391_Translation_Studies_Research_at_the_ Service_of_Translation_Profession_A_Case_Study_at_Undergraduate_Level. Acesso em: nov. 2019.

CHESTERMAN, Andrew; WAGNER, Emma. Can theory help translators: a dialogue between the Ivory Tower and the Workforce. Manchester: St Jerome Publishing, 2002.

COCOLA, Jim. Eyes on the University. The Minnesota Review n. 67 Fall. Duham: Duke University Press, 2006. p. 143-152.

COLLET, Thaís. O mercado de tradução audiovisual no Brasil: formação e demanda. 2016. Tese (Doutorado em Estudos da Tradução) - Universidade Federal de Santa Catarina. Florianópolis, 2016. Disponível em: https://repositorio.ufsc.br/xmlui/bitstream/handle/123456789/173257/343707.pdf?sequence=1 \&isAllowed=y Acesso em: nov. 2019.

COSTA, Patrícia Rodrigues. A formação de tradutores em instituições de educação superior públicas brasileiras: uma análise documental. 2018. Tese (Doutorado em Estudos da Tradução) - Universidade Federal de Santa Catarina. Florianópolis, 2018. Disponível em: https://repositorio.ufsc.br/bitstream/handle/123456789/188094/PGET0372-T.pdf?sequence=1. Acesso em: nov. 2019. 
DERRIDA, Jacques. A universidade sem condição. Traduzido por Evandro Nascimento. São Paulo: Estação Liberdade, 2003.

DERRIDA, Jacques. Du droit à la philosophie. Paris: Galilée, 1990. Disponível em: https://redaprenderycambiar.com.ar/derrida/frances/droit_philosophie.pdf. Acesso em: nov. 2019.

DERRIDA, Jacques. O olho da universidade. Traduzido por: Ricardo I. Canko e Ignácio A. Neis. São Paulo: Estação Liberdade, 1999. Disponível em: http://www.biblioteca.uesc.br/biblioteca/bdtd/201360030D.pdf. Acesso em: nov. 2019.

ESQUEDA, Marileide Dias; OLIVEIRA, Karoline Izabella. Crenças e concepções do tradutor em formação. Tradução em Revista, Rio de Janeiro, v. 14, n. 1, p. 137-164, 2013.

Disponível em: https://www.maxwell.vrac.puc-rio.br/22051/22051.PDFXXvmi=. Acesso em: nov. 2019.

FAWCETT, Antoinette; GARCIA, Karla L. Guadamarra. Introduction. In: FAWCETT, Antoinette; GARCIA, Karla L. Guadamarra; PARKER, Rebecca Hyde (Ed.). Translation: Theory and Practice in Dialogue. New York/Londres: Continuum, 2010. p. 1-22.

GILE, Daniel. Theoretical components in interpreter and translation training. In: GILE, Daniel. Basic Concepts and Models for Interpreter and Translation training.

184 Amsterdã/Filadélfia: John Benjamins, 2009.

GONÇALVES, José Luiz Vila Real; MACHADO, Ingrid Trioni Nunes. Um panorama do ensino de Tradução e a busca da competência tradutória. Cadernos de Tradução (UFSC), Florianópolis, v. 1, n. 17, p. 45-69, 2006. Disponível em:

https://periodicos.ufsc.br/index.php/traducao/article/view/6856/6408. Acesso em: nov. 2019.

GUERINI, Andréia; TORRES, Marie-Hélène Catherine; COSTA, Walter Carlos (Org.). Os estudos da Tradução no Brasil nos séculos XX e XXI. Tubarão, SC: Copiart, 2013.

LIMA, Erica; SPOLIDORIO, Samira. Os desafios do ensino da tradução na universidade: educar ou treinar? In: SCHAFFER, Ana Maria de Moura; TORRES, Milton L. (Org.). A dimensão teórica e prática da tradução: uma cartografia didática. Engenheiro Coelho: GETI/UNASP, 2019. p. 14-26.

MARTINS, Márcia Amaral Peixoto. Novos desafios na formação de tradutores. Cadernos de Tradução, Florianópolis, v. 1, n. 17, p. 25-44, 2006. Disponível em: https://periodicos.ufsc.br/index.php/traducao/article/view/6855/6407. Acesso em: nov. 2019.

MERCADO de tradução: é preciso formação na área? Blog Seja Tradutor, 2019. Disponível em: http://sejatradutor.com.br/mercado-de-traducao-formacao-na-area/. Acesso em: ago. 2019.

PAGANO, Adriana. Crenças sobre a tradução e o tradutor: revisão e perspectivas para novos planos de ação. In: PAGANO, Adriana; MAGALHÃES, Célia; ALVES, Fábio. Traduzir com autonomia: estratégias para o tradutor em formação. São Paulo: Contexto, 2003. p. 928. 
PRESAS CORBELLA, Marisa.; MARTÍN DE LEÓN, Celia. The role of implicit theories in the non-expert translation process. MonTI, Special Issue, Alicante, v. 1, p. 273-302, 2014.

PRESAS, Marisa. Implicit theories and conceptual change in translator training. In:

SCHWIETER, John W.; FERREIRA, Aline (Eds.). The Handbook of Translation and

Cognition. Hoboken, NJ: John Wiley \& Sons: 2017. p. 519-534.

PUNGARTNIK, Cláudia. A relação teoria e prática na formação do tradutor em

universidades brasileiras. 2015. Dissertação (Mestrado em Letras - Linguagens e

Representações) - Universidade Estadual de Santa Cruz, Ilhéus, 2015. Disponível em:

http://www.biblioteca.uesc.br/biblioteca/bdtd/201360030D.pdf Acesso em: nov. 2019.

PYM, Anthony. Translator Training. Versão no prelo do texto publicado em: MALMKJÆR, Kirsten; WINDLE, Kevin. The Oxford Handbook of Translation Studies. Oxford: Oxford University Press, 2009. Disponível em: https://www.researchgate.net/publication/242711915 _Translator_training. Acesso em: nov. 2019.

VENUTI, Lawrence. Introduction - Translation, Interpretation and the Humanities. In: VENUTI, Lawrence. Teaching Translation - Programs, Courses, Pedagogies. New York: Routledge, 2017. p. 1-14.

\footnotetext{
*Samira SPOLIDORIO - Doutoranda e Mestre (2017) em Linguística Aplicada pela Universidade Estadual de Campinas. Especialista em Língua Inglesa e Tradução (2015) e em Língua Portuguesa (2009) pela Universidade Metodista de Piracicaba. Graduada em Letras - Língua Portuguesa (2007) pela Universidade Metodista de Piracicaba. Campinas, São Paulo, Brasil.

Currículo acadêmico: http://lattes.cnpq.br/1852611009932326

ORCID: https://orcid.org/0000-0002-2640-2337

E-mail: samira.spolidorio@gmail.com

1 Pesquisa realizada no Departamento de Linguística Aplicada do Instituto de Estudos da Linguagem da Universidade Estadual de Campinas e financiada pela Coordenação de Aperfeiçoamento de Pessoal de Nível Superior (CAPES).

2 A palavra Tradução aparecerá no texto sempre com letra maiúscula quando se referir a área de Estudos da Tradução e sempre com letra minúscula, tradução, quando se referir ao texto traduzido ou ao processo tradutório.

${ }^{3}$ Como bem explica Chaia $(2014,2015)$, o equivalente ao tradutor juramentado no Brasil (especializado em documentos e conteúdo de valor legal e jurídico) é regulamentado e obrigatoriamente necessita de formação universitária no curso de "Tradutor Público" na Argentina. Porém, para as demais especialidades da tradução (literária, técnica, marketing, audiovisual, entre outros), assim como no Brasil e em outros países, a formação não é obrigatória.

${ }^{4}$ Original: "formal training is not mandatory, but it can perform at least two important functions. One is to help individuals who wish to become professional interpreters or translators enhance their performance to the full realization of their potential. The other is to help them develop their Translation skills more rapidly than through field experience and self-instruction, which may involve much groping in the dark and learning by trial-anderror".

${ }^{5}$ Conforme experiência da autora atuando como professora universitária em um curso de graduação em Tradução e Interpretação em uma universidade particular e como auxiliar de docência em disciplina eletiva sobre Tradução de um curso de Letras de uma universidade pública.

${ }^{6}$ Original: "knowledge becomes the foremost economic resource, serving as the precondition of and sustaining factor in economic and/or military hegemony. Yet, in a digital age, there is no particular reason why universities must serve as centers of all known and potential knowledge, or indeed as centers of anything at all".

${ }^{7}$ Publicação feita no grupo do Facebook 'Tradutores / Intérpretes' em 05/09/2016. Omitimos o nome completo da autora da enquete e dos demais comentários para preservar a identidade dos envolvidos.

${ }^{8}$ Embora não esteja explícito em nenhuma dos anúncios acima, é bastante provável que a uma das razões para o aumento dessa exigência nos últimos anos por agências de tradução internacionais de grande porte seja a norma
}

SPOLIDORIO, Samira. O lugar da teoria e da prática em cursos de graduação em tradução. Belas Infiéis, Brasília, v. 9, n. 1, p. 167-186, 2020. 
do ISO 17100 (instituída em 2015 e revisada em 2017, disponível em: https://www.iso.org/standard/59149.html), uma vez que um dos critérios para a atribuição do selo de qualidade e conformidade ISO é a qualificação específica e comprovada dos profissionais envolvidos nos processos de tradução e revisão.

${ }^{9}$ Original: "not just to ensure a certain quality of performance but also to control the allegiance of the translators".

${ }^{10}$ Embora o livro em questão tenha Andrew Chesterman e Emma Wagner como autores e, portanto, a citação apresente o nome dos dois, é importante destacar que a organização do livro é em forma de debate em que Chesterman defende a teoria enquanto Wagner rebate seus argumentos em favor da prática. Assim, os argumentos e citações creditados aqui a ambos os autores são, na verdade, de autoria e representam a opinião apenas de Chesterman.

${ }^{11}$ Original: "an acquaintanceship with theory, and in particular with a wide range of theories, and not some single master-theory, could become a powerful tool in the hands of translators, giving them insight into the manifold ways in which their practice might be constructed. Such theories may be theories of or about translation, or may be theories from outside the field, brought in to enable both practitioner and scholar to better understand the phenomenon of translation as such. Furthermore, we also wish to suggest that practice itself inevitably will, and should, influence theory".

${ }^{12}$ Original: "as everyday understanding, implicit theories, folk theories, subjective theories and beliefs".

${ }^{13}$ Original: "the role of implicit theories in decision-making covers a broad area ranging from personal to political relationships, and from private to professional life. To date, translation studies have paid little attention to the influence of translators' knowledge and beliefs in the translation process, and even less to the role of implicit theories".

14 Original: "on conceptual change focuses on the processes by which learners restructure their initial conceptions".

${ }^{15}$ Os cursos de graduação e pós-graduação passaram por um grande desenvolvimento desde o final do século XX até hoje. Uma amostragem desse percurso pode ser vista no livro organizado por Guerini, Torres e Costa (2013), Os Estudos de Tradução no Brasil nos séculos XX e XXI.

$186{ }^{16}$ Original: "students have implicit theories that they apply to their translation process. It can be assumed that, for students, these theories function as an instrument to interpret situations and define objectives. However, the evidence also shows that, in general, these theories characterize translation and related phenomena superficially and partially and are applied regardless of contextual considerations. Consequently, these theories are a contributing factor to inadequate, or at least unpredictable, results". 